\title{
Individualization, differentiation and material adaptation in teaching mixed ability groups
}

Alikulova Diana Maratovna-Assistant Department of Foreign Languages, Tashkent University of Information Technologies named after Mukhammad al- Kwharizmi

\begin{abstract}
This article is aimed to reveal the strategies such as individualization, differentiation and material adaptation to teach mixed ability classes. Furthermore, the article depicts the results of the experiment followed by questionnaire and observation carried with the learners of vocational English in Tashkent university of informational technologies named after Muhammad alKhwarizmi. The product of the research became the basis for implication of the mentioned above strategies in the syllabus of the course.
\end{abstract}

Key words. Heterogeneity, mixed-ability, collaborative learning, individualization, differentiation, material adaptation, language background, language performance, motivation.

\section{Introduction}

For the entire existence of the teacher's profession, the question of using appropriate strategies has always been at the center of discussion. Speaking, we correspond to the appropriate techniques, the use of which will be prudent in the current educational conditions, will satisfy the needs of all students regardless of their language experience, interest, motivation and ideology. This problem was well disclosed in the works of John Amos Comenius. In addition, modern teachers studied language learning strategies as a set of operations and techniques (Wenden, Ruban, Richards, Platt, Rogda). This set represents an individual approach to each student in the learning process. It is also important for the teacher to make the most of the teaching materials so that they can be appropriately applied to students at various levels. Consequently, there are not groups of students which can be homogeneous (homogeneous) from the point of view of different aspects, such as language experience, speed of learning and perception, ability to learn and motivation, regardless of which educational institution is meant. Therefore, teachers in both language and non-linguistic institutions of higher education should be aware of the problems of classes with mixed abilities and their solutions in order to identify the source of the problems and prevent them.

\section{Literature review}

In general, language learners may differ in many aspects that affect the ability to learn a language. Students have different strengths, weaknesses and preferences for learning. They respond differently to specific training methods and classroom situations. Before defining this concept, it would be better to look at its origin.

The concept of the so-called classes with mixed skills was not originally related to teaching English as a second or foreign language. The term initially referred to what was perceived as the creation of an alternative to the usual classes in which streaming was performed. As Harlen and Malcolm (1992) explain in their studies, streaming is a term that describes a method of dividing students into 
classes based on an assessment of their general abilities. It was popular in the UK in the 1960s. Further research has shown that this has a negative effect on student performance in secondary schools, therefore, it is becoming less and less popular in primary schools and eventually disappears in the 1970s and 1980s.

In addition to streaming, the term "regulation" appears in the same period. Regulation (setting) means the regrouping of students on the basis of their abilities in a particular subject. Speaking about students with mixed abilities, grouping means randomly selected students are grouped into one group, regardless of their abilities or achievements in the relevant subject. However, there are basically two terms that are used to describe classes with different linguistic abilities. The first is classes with mixed abilities. The term "mixed abilities" is defined as "engaging students with different levels of ability". The second term is heterogeneity (homogeneity), which is defined as "consisting of parts or things that are very different from each other." Both terms are used to define classes with different linguistic abilities. However, different authors prefer different terms. For example, Luke Prodromou calls these classes as classes with mixed abilities (1992), while Penny Urv prefers the term heterogeneous (1991). She believes that the term "mixed skills" does not cover all aspects of heterogeneity in relation to a class of language learners, but rather refers only to the ability to perform a particular task. In contrast, she argues, the term heterogeneous also includes other factors that influence language learning, such as previous learning experience, problems and achievements of previous learning, high or low motivation, etc.

Classes with mixed abilities are usually described as classes with learners who have different language abilities. However, students are distinguished not only by their ability to master the language, but also by age, motivation, intelligence, self-discipline, literacy skills, learning style, attitude and interests. While some differences are easy to see, others are hard to spot. The first aspect that is associated with differences among students is age.

Age is one of the main factors that influence what and how we learn. People of different ages have different needs, competencies and cognitive skills. There are certain beliefs about language learning in relation to certain age groups. It is believed that young students learn faster than other age groups. According to Harmer: "This is somehow related to the plasticity of the young brain." In addition, according to the Critical Period Hypothesis, there is a certain and limited time period for learning a language. However, speaking about the group of students of one faculty and one course, this hypothesis as well as the age indicator is not the main parameter that should be taken into account when differentiating groups with mixed abilities. Thus, it is more important to pay attention to the language skills of students.

Language skills can be described as "innate talent or predisposition to learn a language." There is evidence in the scientific literature that some people have an exceptional "ability" to learn a language. In the 1950s and 1960s, the idea that it is possible to predict the future success of students on the basis of tests for linguistic abilities was formed. The two most widely used abilities tests were the Modern Language Aptitude Test, developed by John Carroll, and the Pimsleur Language 
Aptitude Battery, developed by Pimsler in the 1960s. They measure the ability to recognize and memorize new sounds, understand the function of individual words in sentences, determine the grammatical rules from language examples, and memorize new words.

These two traditional tests of language skills were criticized for measuring general intellectual abilities rather than linguistic talent and, consequently, led to the fact that teachers often divided students into "bad" and "good". Another negative factor in the traditional test of language abilities was that students who received poor grades in their ability tests could lose their motivation, because it was assumed that the test was able to predict students' future achievements, as well as

failure.

An important role in determining the distinctive abilities of students in one group is intelligence. Language ability is associated with intelligence, which in turn is another factor in language acquisition. Intellect can be described as "general intellectual ability." According to Lighttown and Spada (1999), people who have proven themselves in IQ tests should also successfully master a second language. However, IQ tests measure metalinguistic knowledge, not communication skills. This suggests that traditional IQ tests measure the skills needed to analyze a language and learn the rules. However, this type of intelligence plays a less important role in classes where emphasis is placed on communication and interaction.

Recently, many teachers and other educational professionals have been influenced by the concept introduced by Harvard psychologist Howard Gardner. According to this concept, people have not only one intellect, but a range of intellect, which Gardner called the multiple intellect. Thus there is the following division:
1. linguistic
2. visual-spatial
3. musical
4. logical-mathematical
5. body kinesthetic
6. interpersonal (ability to recognize other people's feelings, motives, intentions)

7. intrapersonal (ability to recognize your feelings, motives, intentions)

8. naturalistic

People have all these eight intelligences, but we tend to use one or two. It should be noted that many perceived the theory of Gardner's multiple intellect as a character trait characteristic of each person, either an innate or acquired talent, but not factors of mastering the language. Therefore, in order to better understand the conditions affecting the acquisition of language skills, let us turn our attention to existing learning styles among students.

Harmer explains: "We use a number of primary representative systems for understanding the world." These systems are visual, auditory, kinesthetic, olfactory and gustatory. People use all these systems to explore the world. However, we 
have one preferred primary system that we subconsciously apply. In connection with language teaching, teachers should be aware of the sensory preferences of their students. Taking into account the risk that the teacher is also inclined to one or another style, he may focus his methodology on his preferred system, after which students may not benefit from the lesson. Therefore, it would be wiser to determine the learning style of their students at the beginning of the course. There are many questionnaires designed to determine the style of teaching students - the definition of style greatly facilitates the learning process for both teachers and students.

One of the most important, if not decisive, aspects affecting the way and speed of training people is motivation, usually defined as "the forces that determine the selection, direction and essence of behavior". A student who is motivated to study is a student who has found a reason to study, and the effort that a student uses to learn something is directly dependent on the level of motivation, the more motivated the student is, the harder he will learn.

Upon arrival in class, the teacher is confronted with a group of students who have high or moderate motivation or lack of motivation to participate in the activities that he / she prepared / prepared for them, depending on whether the students have their own reasons for studying a particular subject.

We distinguish between two types of motivation. Extrinsic motivation is something that arises under the influence of some external stimulus, as opposed to the desire to learn for yourself or from interest in a task. Sources of extrinsic motivation can be: the desire to satisfy parents, take an exam, get a job, etc.

Language is learned in order to receive some kind of reward. On the other hand, intrinsic motivation is associated with motivation that emanates from within a person. Sources of intrinsic motivation come from the student. Language is learned for the pleasure and satisfaction of the student.

Motivation is a necessary factor for successful language acquisition. It should be encouraged from the very beginning of language learning, otherwise it may adversely affect the learning process. One of the key issues for encouraging motivation is a positive understanding, a respectable and open attitude of the teacher and the choice of interesting and useful activities based on student preferences.

The purpose of the research is to identify the role of individualization, differentiation and material adaptation in teaching mixed ability groups.

\section{The research methods}

The practical part is based on the following research methods:

e questionnaires

e observation

ᄅ self-evaluation

The two groups, namely 210 and 208 that are the learners of Tashkent university of information technologies named after Mukhammad al- Kwharizmi, was observed especially during various activities. On the grounds of observation, the students were sometimes divided into pairs with approximately equal language skills and other times into pairs formed by students with different language level 
according to the most beneficial consideration at the given moment. A course evaluation questionnaire was distributed to all students. The questionnaire was designed for students to evaluate their language progress, the lessons - their structure and organization, the materials and choice of activities, teacher preparation, their perception of mixed ability environment and general satisfaction with the course.

\section{Results}

The one term study was important to check the effectiveness of the suggested strategies such as individualization, differentiation, material adaptation. The strategies were chosen in according with previous mentioned diversity aspects of mixed ability groups- learning style, ability, perception and motivation. Consequently, the research held the questionnaire to check the outcomes of the strategies chosen.

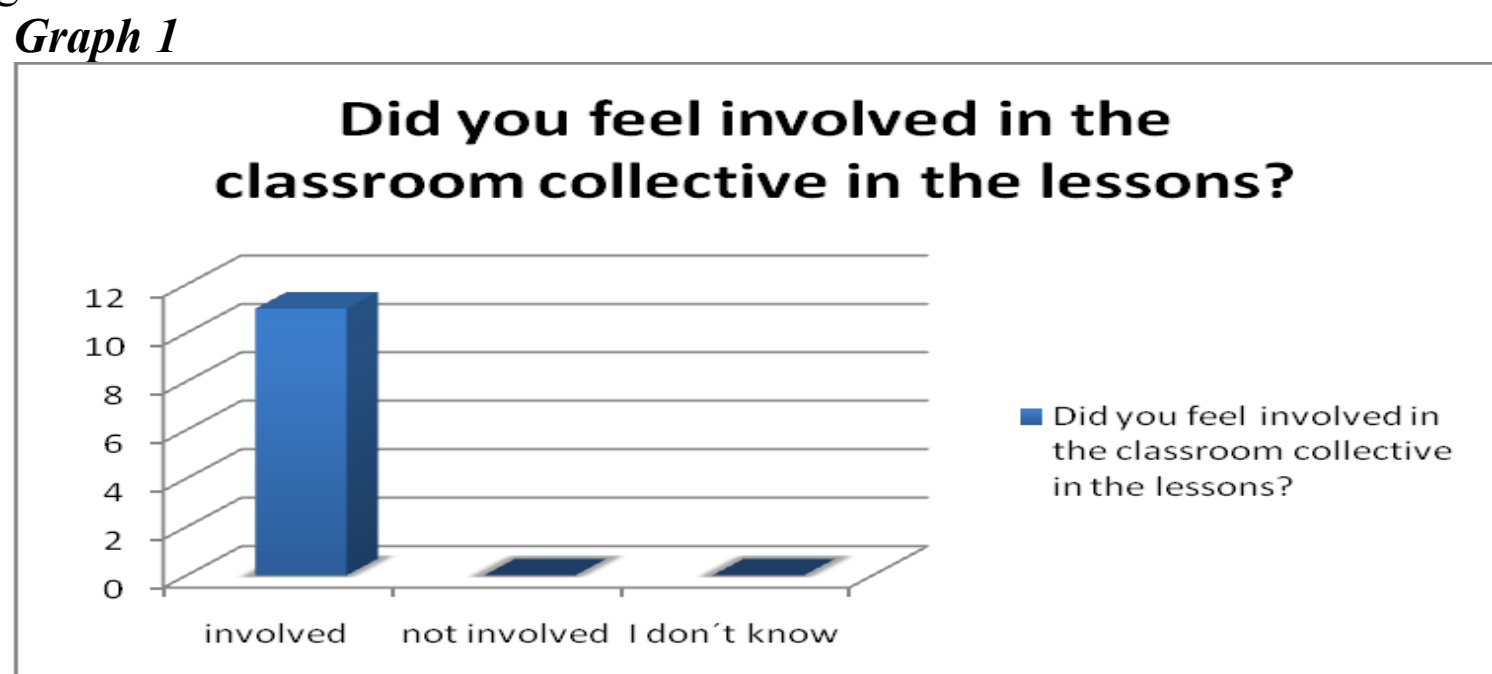

The graph illustrates that the class is tight-knit. $100 \%$ of students felt involved in the classroom collective.

Graph 2

\section{Did you feel involved in all activities in the lessons?}

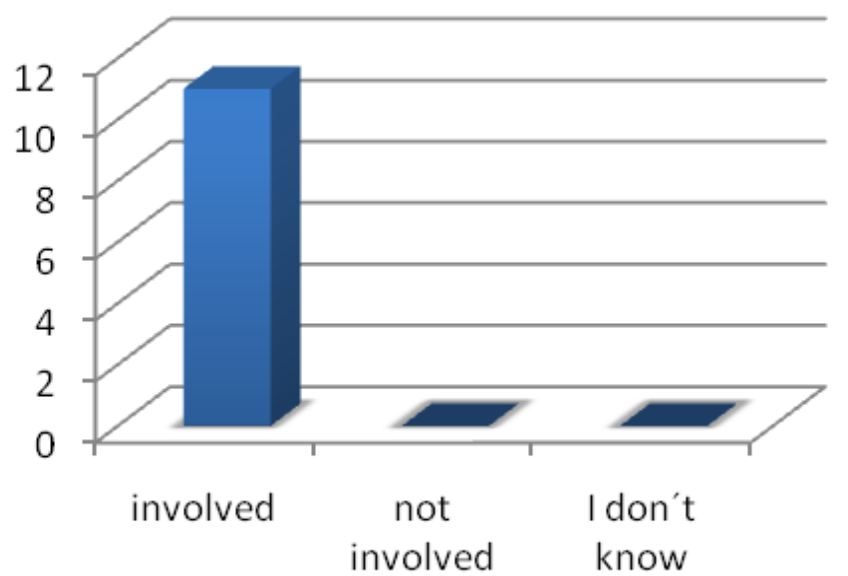

Did you feel involved in all activities in the lessons?

$100 \%$ of students felt involved in all activities. 
Graph 3

\section{Were the exercises done in the lessons interesting and contributing to you?}

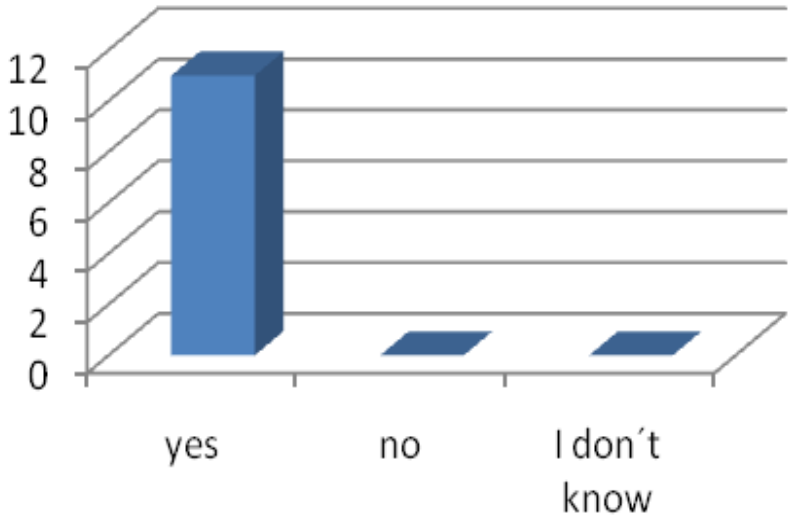

$100 \%$ of students found the exercises interesting and contributing and as the graph 3 shows $0 \%$ of them thought that the activities were boring.

Graph 4

\section{Did the teacher adjust to all students'needs?}

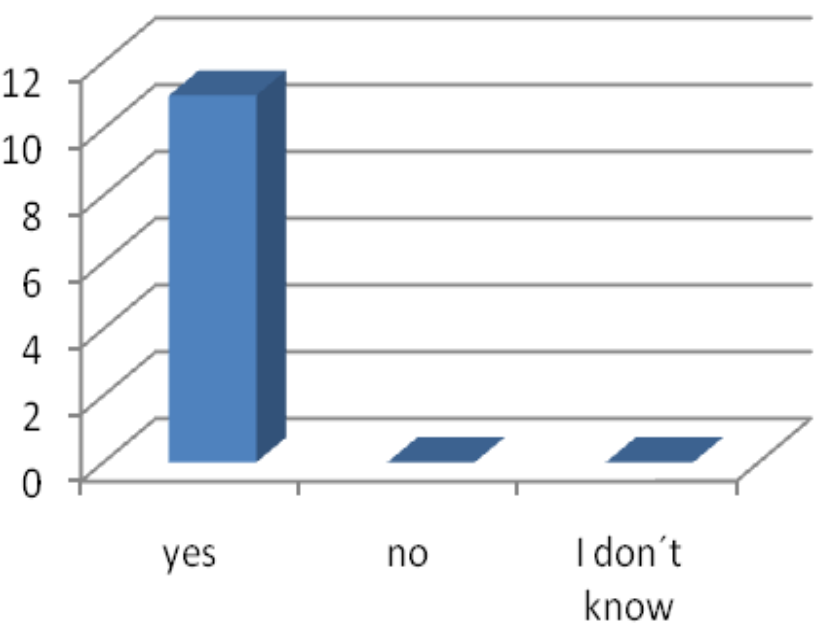

Did the teacher adjust to all students'needs?

$100 \%$ of students think that the teacher adjusted to all students' needs. Graph 5 


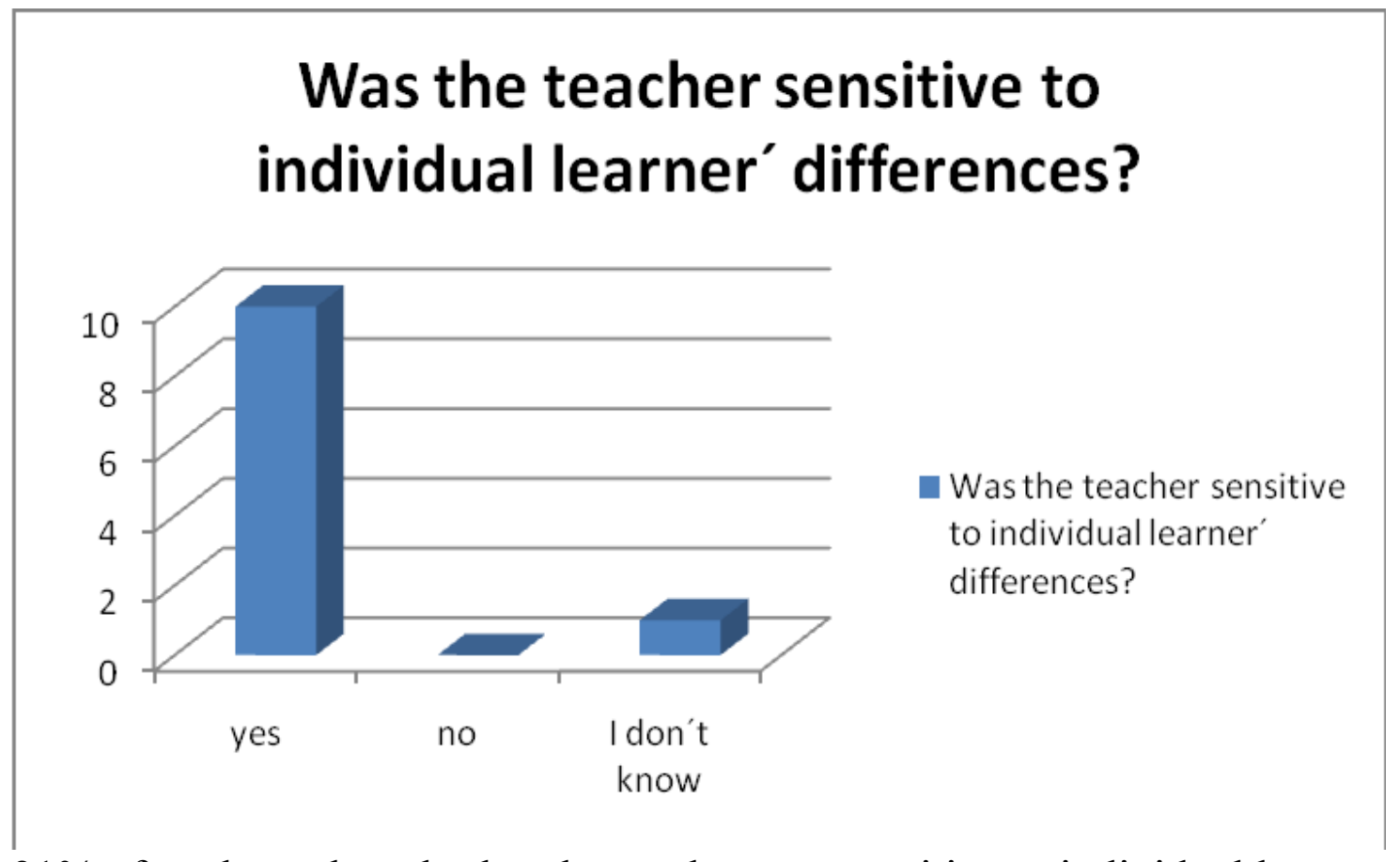

$91 \%$ of students thought that the teacher was sensitive to individual learner differences. $9 \%$ of students answered "I don't know".

\section{Graph 6}

\section{Was the atmosphere in the lessons motivating and supportive?}

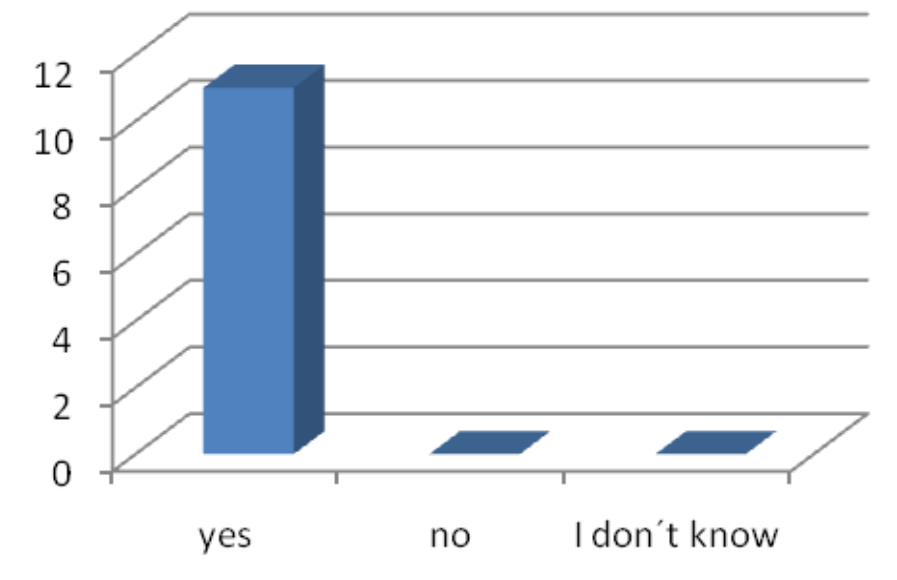

Was the atmosphere in the lessons motivating and supportive?

$100 \%$ of students found the atmosphere in the lessons motivating and supportive.

There are possible biases involved in the interpretation of data from the questionnaires. When analyzing the results, we have to take into consideration that students' answers are subjective and this affects accuracy of the data.

While analyzing the date of the research we come across several inconsistencies. In the graph , $100 \%$ of students reported that the teacher adjusted lessons to every student's needs, while from the graph 5 it is depicted that $91 \%$ of students finds the teacher was sensitive to individual learner differences, whereas almost $10 \%$ of learners are not sure about the teacher's attitude. The results imply 
that it is necessary to consider the importance of supportive class environment and friendly peers besides the actual learning process in the mixed ability class. This also implies that teachers of mixed ability classes have to establish a pleasant atmosphere in the classroom, demonstrate flexibility, open-mindedness, and explore non-traditional teaching styles.

\section{Conclusion}

We have already noted that all classes are groups with mixed abilities. Teaching in these classes requires the use of a set of methods and techniques, the adaptation of educational material taking into account the individual abilities and motivation of each student. Although learning in a class with mixed skills presents many learning difficulties, it leads to the search for non-traditional learning strategies and methods. It is evident that based on preliminary questionnaires, the research met students' requirements successfully. As results from the course evaluation questionnaire, students are happy and satisfied with the lessons. They especially enjoy variety of interesting activities, adapting materials, the teacher's attitude towards teaching and the general atmosphere.

\section{References}

1. Cerezal Sierra, "Foreign language teaching methods"-1999 in AlenaKasparkova, Dealing with Mixed Ability Classes. Poland: Brno -2010, p- 20

2. Harlen, Malcolm, Classroom Dynamics. Oxford: Oxford University Press1992, p 11

3. Lighton and Spada, How languages are learned. Oxford: Oxford University Press- 1999, p 18

4. Richards and Platt, The Dierentiated Classroom: responding to the Needs of All Learners. Alexandria: ASCD-1999, p 27

5. Scarcella, Robin C., and Rebecca Oxford. The Tapestry of Language Learning.

6. Scrivener, Jim, Learning Teaching. Oxford: Macmillan Education, 2005, p 399

7. Ur, Penny. A Course in Language Teaching. Cambridge: Cambridge University Press- 1991, p 34 